\title{
Time Course of Central Precocious Puberty Development Caused by an MKRN3 Gene Mutation: A Prismatic Case
}

\author{
Monica F. Stecchini ${ }^{a}$ Delanie B. Macedo ${ }^{b}$ Ana Claudia S. Reis ${ }^{a}$ \\ Ana Paula Abreu $^{c}$ Ayrton C. Moreira ${ }^{a}$ Margaret Castro $^{a} \quad$ Ursula B. Kaiser $^{c}$ \\ Ana Claudia Latronico ${ }^{b}$ Sonir R. Antonini ${ }^{a}$ \\ ${ }^{a}$ Departments of Pediatrics and Internal Medicine, Ribeirão Preto Medical School, University of São Paulo, \\ Ribeirão Preto, and ${ }^{\mathrm{b}}$ Unidade de Endocrinologia do Desenvolvimento, Laboratório de Hormônios e Genética \\ Molecular, LIM42, Hospital das Clínicas, Disciplina de Endocrinologia, Faculdade de Medicina da Universidade \\ de São Paulo, São Paulo, Brazil; ' Division of Endocrinology, Diabetes, and Hypertension, Brigham and Women's \\ Hospital and Harvard Medical School, Boston, Mass., USA
}

\section{Key Words}

Gonadotropin-dependent precocious puberty $\cdot$ MKRN3

mutation · Penetrance $\cdot$ Early diagnosis $\cdot$ Genetic counseling

\begin{abstract}
Background: Loss-of-function mutations in the imprinted gene MKRN3 represent the most common known genetic defects associated with central precocious puberty (CPP). Methods: We report the first case of a girl carrying an MKRN3 mutation detected in childhood and followed until the development of pubertal signs. Results: The girl was screened at the age of 4 years because of a positive family history; her sister had developed CPP at 6 years of age and was found to harbor the MKRN3 p.Pro161Argfs*16 mutation, inherited from their asymptomatic father. During close follow-up, she initially developed increased growth velocity at 6 years $(9 \mathrm{~cm} /$ year), followed by a slightly increased basal luteinizing hormone level $(0.4 \mathrm{mIU} / \mathrm{ml})$ and, ultimately, clinical thelarche with rapid progression (Tanner stage 1-3) between 6.3
\end{abstract}

() 2016 S. Karger AG, Basel

E-Mail karger@karger.com www.karger.com/hrp and 6.7 years. In the context of a loss-of-function MKRN3 mutation and a positive family history, these features established the diagnosis of CPP and supported the initiation of treatment with a gonadotropin-releasing hormone analog. The absence of significant bone age advancement, pubic or axillary hair, or behavioral or social problems could be ascribed to the early diagnosis. Conclusion: The identification of carriers of MKRN3 mutations may contribute to early diagnosis of CPP, facilitating treatment decisions and guiding genetic counseling and prompt intervention in familial cases.

(c) 2016 S. Karger AG, Basel

\section{Introduction}

Gonadotropin-dependent precocious puberty or central precocious puberty (CPP) is a condition caused by early reactivation of the hypothalamic-pituitary-gonadal axis, leading to the development of secondary sexual characteristics before the age of 8 years in girls and 9 years 
a

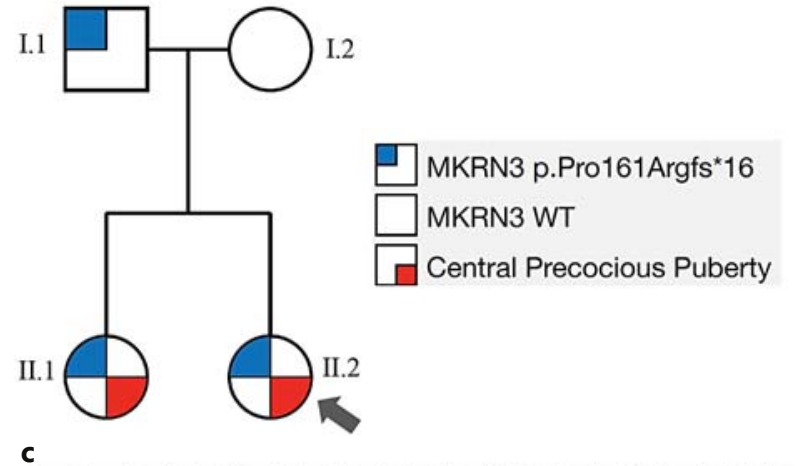

c

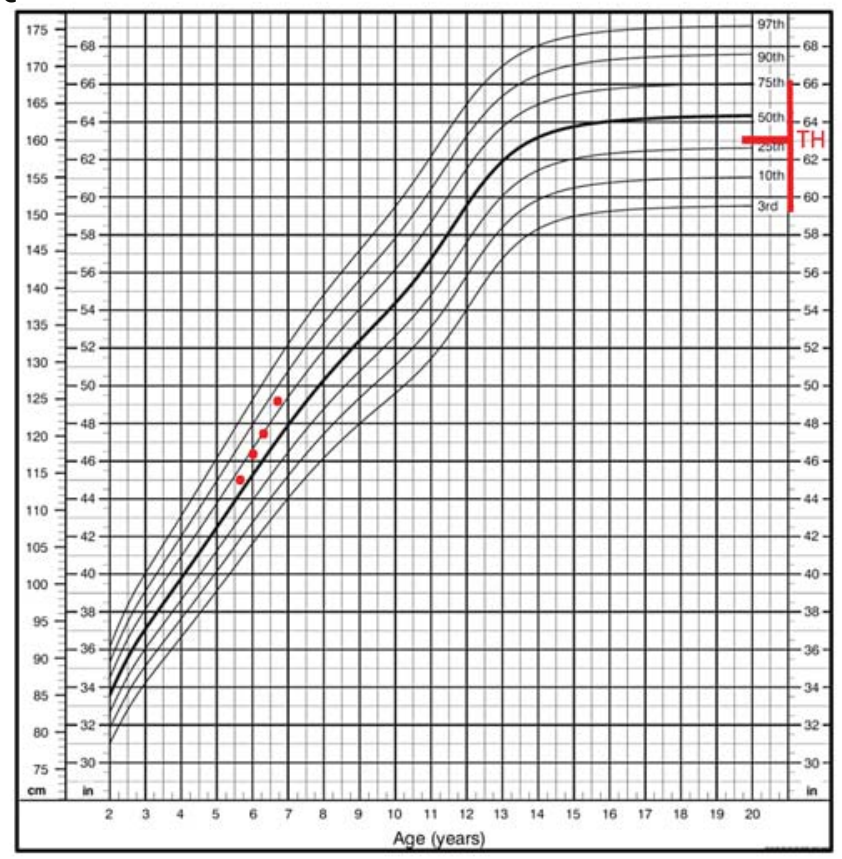

b

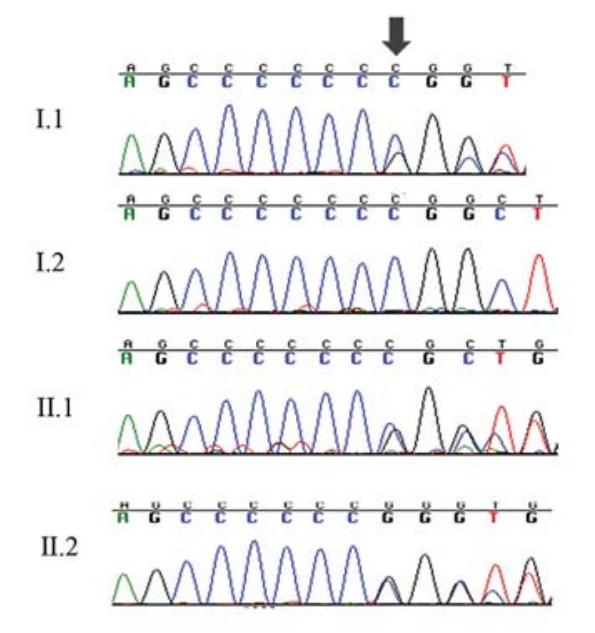

d

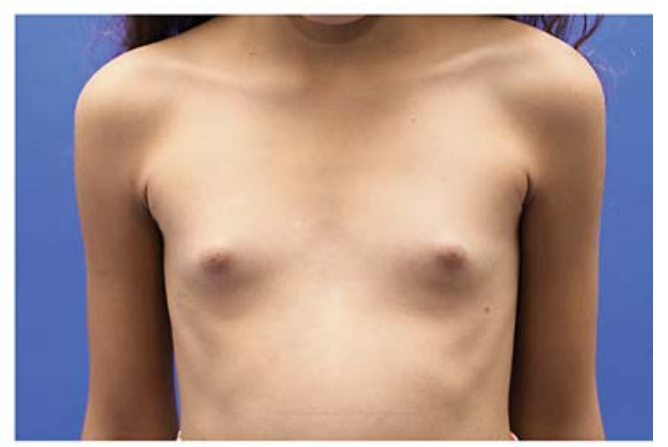

Fig. 1. a Family pedigree showing the segregation of CPP with the paternally inherited $M K R N 3$ p.Pro161Argfs*16 mutation. b Chromatograms showing the presence of the MKRN3 p.Pro161Argfs*16 mutation in the asymptomatic father (I.1) and in his two daughters who developed CPP (II.1 and II.2). c Girl's stature-for-age growth chart showing the increased growth in the reported girl (II.2) with

in boys [1]. Its estimated incidence is 1:5,000-1:10,000 in American girls [2]. If untreated, it may result in short stature and psychosocial maladjustment. Additionally, an early age of menarche has been associated with adverse health outcomes later in life, such as increased risk of cardiovascular morbidity and mortality and cancer [1].

Despite compelling evidence - provided by population-based studies - of genetic influences on pubertal

Central Precocious Puberty and MKRN3

Mutation
CPP caused by the MKRN3 p.Pro161Argfs* 16 mutation. d Rapid breast development (Tanner B3) in a 6.7-year-old girl (II.2) with CPP caused by the MKRN3 p.Pro161Argfs*16 mutation (the exhibition of this photography was authorized by the patient's parents). WT $=$ Wild type; $\mathrm{TH}=$ target height.

timing, only rare genetic defects (gain-of-function mutations in KISS1 and KISS1R) had been reported in association with CPP until recently $[3,4]$. However, in 2013, Abreu et al. [5] provided a significant advance in this field through the identification of loss-of-function mutations in $M K R N 3$ - an imprinted gene located in the PraderWilli syndrome critical region (chromosome 15q1113) - in about one third of patients with familial CPP. In 
Table 1. Time course of the clinical and laboratory features of a prepubertal girl carrying a loss-of-function MKRN3 mutation who developed CPP

\begin{tabular}{llllllll}
\hline $\begin{array}{l}\text { Age, } \\
\text { years }\end{array}$ & $\begin{array}{l}\text { Height } \\
\text { Z-score }\end{array}$ & $\begin{array}{l}\text { Growth rate, } \\
\mathrm{cm} / \text { year }\end{array}$ & $\begin{array}{l}\text { Tanner } \\
\text { stage }\end{array}$ & $\begin{array}{l}\mathrm{LH}, \\
\mathrm{mIU} / \mathrm{ml}\end{array}$ & $\begin{array}{l}\mathrm{FSH}, \\
\mathrm{mIU} / \mathrm{ml}\end{array}$ & $\begin{array}{l}\text { Estradiol, } \\
\mathrm{pg} / \mathrm{ml}\end{array}$ & $\begin{array}{l}\Delta \text { Bone age, } \\
\text { years }\end{array}$ \\
\hline 5.7 & 0.4 & n.a. & B1 PH1 & n.d. & n.d. & n.d. & n.d. \\
6 & 0.5 & 9 & B1 PH1 & 0.1 & 1.3 & 49.7 & 0.6 \\
6.3 & 0.6 & 7.5 & B1 PH1 & 0.4 & 5.9 & 41.3 & n.d. \\
6.7 & 0.8 & 12 & B3 PH1 & 0.9 & 3.3 & 54.1 & 0.7 \\
\hline
\end{tabular}

Normal prepubertal reference values: $\mathrm{LH}<0.3 \mathrm{mIU} / \mathrm{ml}$; estradiol $<20 \mathrm{pg} / \mathrm{ml}$. $\Delta$ Bone age $=$ Difference between bone age and chronological age; n.a. = not available; $\mathrm{B}=$ breast; $\mathrm{PH}=$ pubic hair; $\mathrm{n} . \mathrm{d}$. = not done.

2014, in a multicenter study, we identified five novel MKRN3 mutations in patients with CPP but without an apparent family history of CPP [6]. Since then, several additional deleterious MKRN3 mutations have been described in boys and girls with CPP from different ethnic backgrounds [7-13].

Segregation analysis indicated exclusive paternal transmission and autosomal dominant inheritance in MKRN3-mutated patients [5, 6]. With one exception, all reported individuals carrying $M K R N 3$ mutations were postpubertal [5-13]. Herein, we describe the case of a girl carrying an MKRN3 mutation detected prior to the onset of puberty. Her careful follow-up enabled an early diagnosis and treatment of CPP. In addition, these data deepen the available information on the penetrance of $M K R N 3$ mutations and on the clinical characteristics of the precocious puberty onset and progression resulting from these mutations. This knowledge can be helpful for the management of prepubertal children carrying mutations in this gene.

\section{Case Report}

We present the case of the youngest reported carrier of an MKRN3 mutation, who was first described by Macedo et al. [6] in 2014. At the time of that report, the girl was 4 years old and prepubertal, and she was evaluated because her older sister had been diagnosed with CPP at the age of 6 years and carried the p.Pro161Argfs*16 mutation in MKRN3. She was found to harbor the same mutation, which was inherited from their asymptomatic father (fig. 1a, b). Of note, information on pubertal development in other relatives was not available.

Due to the presence of the mutation, she was followed closely at the Hospital of the Ribeirão Preto Medical School, University of São Paulo, Brazil. Her parents were informed of the risk for the development of CPP and were told to seek medical assistance if any pubertal changes were detected during the 4-month intervals between scheduled visits. The patient gave her consent, and her par- ents signed an informed consent to participate in this study, which was approved by our institutional ethics committee.

At her first appointment, at age 5.7 years, her history did not reveal any other risk factors for CPP, and her physical examination was normal (table 1) with height within the familial range (target height: $160.5 \mathrm{~cm}$ ) and Tanner stage 1 breast development and pubic hair. Despite the unremarkable exam, bone age (left hand and wrist radiography) and hormone levels [luteinizing hormone (LH), follicle-stimulating hormone (FSH), and estradiol] were ordered to assess pubertal development in this unprecedented situation. LH and FSH (Siemens Immulite 2000) and estradiol (DPC Immulite 2000) were measured by immunochemiluminescence (ICMA). Analytical sensitivity was $0.1 \mathrm{mIU} / \mathrm{ml}, 0.2 \mathrm{mIU} / \mathrm{ml}$, and $8 \mathrm{pg} / \mathrm{ml}$, respectively.

Four months later (at age 6.0 years), she presented with an estimated growth velocity of $9 \mathrm{~cm} /$ year (above the normal range for her age), but without other signs of puberty. Her bone age was not advanced (between 5 years 9 months and 6 years 10 months) according to the Greulich-Pyle atlas, and her gonadotropin levels were prepubertal (LH $0.1 \mathrm{mIU} / \mathrm{ml}$ and FSH $1.3 \mathrm{mIU} / \mathrm{ml}$ ), although estradiol was within the pubertal range $(49.7 \mathrm{pg} / \mathrm{ml})$.

Another 4 months later (age 6.3 years), she had an estimated growth velocity of $7.5 \mathrm{~cm} /$ year, but she remained at Tanner stage 1. Her basal gonadotropin levels began to rise $(\mathrm{LH} 0.4 \mathrm{mIU} / \mathrm{ml}$ and FSH $5.9 \mathrm{mIU} / \mathrm{ml})$ with pubertal estradiol $(41.3 \mathrm{pg} / \mathrm{ml})$.

Notably, 4 months later, at the age of 6.7 years, she presented with a height of $124 \mathrm{~cm}$ (above the familial range; fig. 1c), with a growth velocity of $12 \mathrm{~cm} /$ year, and Tanner stage 3 for breast development (fig. 1d) and stage 1 for pubic hair. According to the mother, her thelarche had begun 2 months prior to that current visit. Her bone age was between 6 years 10 months and 7 years 10 months, and her basal hormone levels were clearly within the pubertal range: $\mathrm{LH} 0.9 \mathrm{mIU} / \mathrm{ml}, \mathrm{FSH} 3.3 \mathrm{mIU} / \mathrm{ml}$, and estradiol 54.1 $\mathrm{pg} / \mathrm{ml}$. Magnetic resonance imaging (MRI) of the central nervous system did not reveal any abnormality. At this time point, the unequivocal diagnosis of familial CPP was confirmed in the setting of accelerated growth velocity, progressive breast development, increased basal LH, pubertal estradiol, and a family history of CPP in the context of a loss-of-function MKRN3 mutation. Therapy was initiated with a gonadotropin-releasing hormone $(\mathrm{GnRH})$ analog (leuprolide acetate $3.75 \mathrm{mg}$ every 4 weeks). After a few months on GnRH analog therapy, she presented complete involution of the breast development (Tanner 1). 


\section{Discussion}

The identification of loss-of-function mutations in the imprinted gene MKRN3 in patients with familial or apparently sporadic CPP was a significant contribution to the understanding of the genetic regulation of puberty. $M K R N 3$, encoding makorin ring finger protein 3, is proposed to have an inhibitory effect on GnRH secretion. It belongs to a family of E3 ubiquitin ligases, but its mechanisms of action are not yet known [5]. The recent findings suggest that MKRN3 may be an important element of the inhibitory tonus during the quiescent period of childhood and that its downregulation may lead to the reemergence of GnRH pulses [5, 6].

Several distinct MKRN3 mutations have been described in patients with CPP from various ethnic backgrounds [5-13]. They represent the most common genetic defects known to be associated with CPP. All clinically affected individuals inherited the mutation from their fathers, which is in accordance with the fact that this gene is expressed only by the paternal allele (maternal imprinting).

We present the first description of a carrier of an MKRN3 mutation (inherited from the father) who was identified before the development of pubertal signs. The 4 -year-old girl was screened because her sister had developed CPP at the age of 6 years and was found to carry the $M K R N 3$ p.Pro161Argfs*16 mutation. At that time, the risk for this patient to develop CPP was not known. Indeed, no such situation had been reported, and the discovery of MKRN3 mutations as a cause of CPP was very recent $[5,6]$. Subsequent to these first reports and based on additional reports, it appeared that the penetrance of MKRN3 mutations was likely to be complete if paternally inherited. For these reasons, we decided to follow this asymptomatic girl closely.

All patients with MKRN3 mutations present with characteristics typical of early hypothalamic-pituitarygonadal axis activation, such as thelarche before the age of 8 years in girls and testicular enlargement before the age of 9 years in boys, accelerated growth velocity, advanced bone age, and elevated LH, FSH, and estradiol or testosterone. Although both genders are affected, the median age of pubertal onset is 6.0 years (3.0-7.5) in girls and 8.25 years (5.9-9.0) in boys [5-13]. In addition, no abnormalities in the central nervous system and no major signs of Prader-Willi syndrome - despite the location of $M K R N 3$ on chromosome 15 - have been detected in any case, including the present patient [5-13]. Therefore, there are no clinical or biochemical features that distin-

Central Precocious Puberty and MKRN3

Mutation guish CPP associated with MKRN3 mutations from CPP with wild-type $M K R N 3$ [6].

The first clinical sign of CPP in this young carrier of an $M K R N 3$ mutation was increased growth velocity. Although estradiol levels were in the pubertal range since the initial laboratory evaluation, a slight increase in the basal LH level $(0.4 \mathrm{mIU} / \mathrm{ml})$ was only observed 4 months later and clear clinical signs of puberty 8 months later. The inconsistency of estradiol levels seen in this case may be due to the available assay's limitations; nevertheless, in girls, estradiol levels are not used for the diagnosis of CPP [2] due to the overlap between prepubertal and pubertal individuals, especially in assays other than liquid chromatography tandem-mass spectrometry $[2,14]$. In spite of the rise in basal LH level, indicating the beginning of pubertal maturation of the reproductive axis, without the need for a $\mathrm{GnRH}$ stimulation test [15], we elected not to start treatment at this time, given the absence of clear clinical signs of CPP. Clinical thelarche appeared between the ages of 6.3 and 6.7 years. Once started, rapid breast development, from Tanner stage 1 to 3 within 4 months, was noted. Together, these features established the diagnosis of CPP and supported the initiation of treatment with a GnRH analog. The need of MRI in this case was questionable, since the girl was older than 6 years and had a genetic cause for CPP [16]. However, the exam was performed to ensure that there were no other confounders for the development of this disorder.

It is worth noting that the parents did not report any behavioral changes. We believe that the absence of significant bone age advancement, of pubic or axillary hair, or of behavioral or social problems, commonly seen in patients with CPP, can be ascribed to the early diagnosis in this case.

Precocious puberty is one of the most common conditions seen in pediatric endocrinology practice. If not diagnosed and treated properly and in a timely manner, CPP may result in adverse outcomes later in life, including impairment of final height and increased risk of hyperandrogenism and infertility in adult life [17]. In addition, CPP may predispose to social and behavioral problems during adolescence and in adult life [18]. Therefore, the identification of MKRN3 mutation carriers can contribute to an early diagnosis of familial CPP, facilitating treatment decisions and guiding genetic counseling and prompt intervention. This approach would be particularly beneficial for boys, in whom the first pubertal signs are subtle and the diagnosis is frequently delayed. It has been suggested that targeted sequencing of MKRN3 should be introduced into clinical practice to identify the etiology of CPP in familial cases and should also be con- 
sidered in isolated cases [19]. Our prismatic case reinforces this statement. In summary, this clinical case illustrates that the detection of MRKN3 mutations may be an important tool for the early diagnosis and treatment of CPP. It serves as an example of how genetic testing can be useful in the clinical setting.

\section{Acknowledgements}

We would like to thank the patient and her family for their collaboration.
This work was supported by Fundação de Amparo a Pesquisa do Estado de São Paulo (FAPESP) grants 2013/06391-1 (D.B.M.) and 2013/03236-5 (A.C.L.), by Conselho Nacional de Desenvolvimento Cientifico e Tecnologico (CNPq) grant 302849/2015-7 (A.C.L.) and 304158/2012-7 (S.R.A.), and by the Eunice Kennedy Shriver NIH/NICHD grants R01 HD082314 (U.B.K.) and 1F05HD072773 (A.P.A.).

\section{Disclosure Statement}

The authors have no conflicts of interest to report.

\section{References}

1 Willemsen RH, Elleri D, Williams RM, Ong KK, Dunger DB: Pros and cons of GnRHa treatment for early puberty in girls. Nat Rev Endocrinol 2014;10:352-363.

$\checkmark 2$ Macedo DB, Cukier P, Mendonça BB, Latronico AC, Brito VN: Advances in the etiology, diagnosis and treatment of central precocious puberty (in Portuguese). Arq Bras Endocrinol Metabol 2014;58:108-117.

-3 Silvera LG, Noel SD, Silveira-Neto AP, Abreu AP, Brito VN, Santos MG, et al: Mutations of the KISS1 gene in disorders of puberty. J Clin Endocrinol Metab 2010;95:2276-2280.

4 Teles MG, Bianco SDC, Brito VN, Trarbach EB, Kuohung W, Xu S, et al: A GPR54-activating mutation in a patient with central precocious puberty. N Engl J Med 2008;358:709715.

-5 Abreu AP, Dauber A, Macedo DB, Noel SD, Brito VN, Gill JC, et al: Central precocious puberty caused by mutations in the imprinted gene MKRN3. N Engl J Med 2013;368:24672475.

6 Macedo DB, Abreu AP, Reis AC, Montenegro LR, Dauber A, Beneduzzi D, et al: Central precocious puberty that appears to be sporadic caused by paternally inherited mutations in the imprinted gene makorin ring finger 3. J Clin Endocrinol Metab 2014;99:E1097E1103.
7 Settas N, Dacou-Voutetakis C, Karantza M, Kanaka-Gantenbein C, Chrousos GP, Voutetakis A: Central precocious puberty in a girl and early puberty in her brother caused by a novel mutation in the MKRN3 gene. J Clin Endocrinol Metab 2014;99:E647-E651.

8 Schreiner F, Gohlke B, Hamm M, Korsch E, Woelfle J: MKRN3 mutations in familial central precocious puberty. Horm Res Paediatr 2014;82:122-126.

-9 de Vries L, Gat-Yablonski G, Dror N, Singer A, Phillip M: A novel MKRN3 missense mutation causing familial precocious puberty. Hum Reprod 2014;29:2838-2843.

10 Neocleous V, Shammas C, Phelant MM, Nicolaou S, Phylactou LA, Skordis N: In silico analysis of a novel MKRN3 missense mutation in familial central precocious puberty. Clin Endocrinol 2016;84:80-84.

11 Känsäkoski J, Raivio T, Juul A, Tommiska J: A missense mutation in MKRN3 in a Danish girl with central precocious puberty and her brother with early puberty. Pediatr Res 2015; 78:709-711.

12 Simon D, Ba I, Mekhail N, Ecosse E, Paulsen A, Zenaty D, et al: Mutations in the maternally imprinted gene $M K R N 3$ are common in familial central precocious puberty. Eur J Endocrinol 2016;174:1-8.
3 Grandone A, Cantelmi G, Cirillo G, Marzuillo P, Luongo C, Miraglia del Giudice E, et al: A case of familial central precocious puberty caused by a novel mutation in the makorin RING finger protein 3 gene. BMC Endocr Disord 2015; 15:60.

14 Ketha H, Girtman A, Singh RJ: Estradiol assays - the path ahead. Steroids 2015;99:39-44.

15 Harrington J, Palmert MR, Hamilton J: Use of local data to enhance uptake of published recommendations: an example from the diagnostic evaluation of precocious puberty. Arch Dis Child 2013;99:15-20.

-16 Pedicelli S, Alessio P, Scire G, Cappa M, Cianfarani S: Imaging is not indicated in every girl with onset of puberty between the ages of 6 and 8 years. J Clin Endocrinol Metab 2014;99: 4455-4461.

-17 Lazar L, Meyerovitch J, de Vries L, Phillip M, Lebenthal Y: Treated and untreated women with idiopathic precocious puberty: longterm follow-up and reproductive outcome between the third and fifth decades. Clin Endocrinol (Oxf) 2014;80:570-576.

18 Mensah FK, Bayer JK, Wake M, Carlin JB, Allen NB, Patton GC: Early puberty and childhood social and behavioral adjustment. J Adolesc Health 2013;53:118-124.

19 De Bruin C, Dauber A: Insights from exome sequencing for endocrine disorders. Nat Rev Endocrinol 2015;11:455-464. 